Middleton, J. The definitive, peer-reviewed and edited version of this article is published in Environment and Planning A, 43, 12, p. 2857-2877, 2011, http://dx.doi.org/10.1068/a43600. 


\title{
"I'm on autopilot, I just follow the route": exploring the habits, routines, and decision-making practices of everyday urban mobilities
}

\section{Jennie Middleton}

School of Geography, Geology and the Environment, Kingston University, Penrhyn Road, Kingston upon Thames, Surrey KT1 2EE, England; e-mail: J.Middleton@kingston.ac.uk Received 20 December 2010; in revised form 3 June 2011

\begin{abstract}
Much urban and transport policy is based on a series of assumptions relating to predefined journeys informed by rational decision making. For example, the dominant focus of urban pedestrian policy is how the built environment is the primary influence on a person's decision to walk, with these decisions being made at a specific time and place somehow outside the practice of walking. Little attention is given to the importance of the processual and experiential dimensions of walking itself. This paper considers the ways in which journeys into, and through, the city unfold. Specific attention is drawn to how forms of habitual performance, such as practical knowledge and embodied habits and routines, assist in engaging with everyday urban movements. In the context of in-depth research conducted in London, the paper explores the habits and routines of urban pedestrian mobilities such as the daily commute, and in so doing, highlights the complexity and ongoing reconfiguration of these journeys beyond analysis informed by 'rational' intention. In contrast to much transport research that conceives of habit as an external force that somehow obstructs more positive sustainable travel behaviour, discussion focuses on the significance of how everyday urban walking unfolds. It is argued that this form of engagement makes it possible to understand habit as situated and part and parcel of the sequentially organised and occasioned performance of journeys on foot. This, in turn, enables the transformative potential of habitual behaviour to be realised. Throughout the paper consideration is given to specific narratives of everyday urban mobilities; the significance of how such practices are actually 'talked about'; and how these accounts matter in engaging with the experiential dimensions of urban movement.
\end{abstract}

\section{Introduction}

The complexity of engaging with how people move into and through the city has long been acknowledged in transport and urban policy and academic writings. Attempting to understand decision making and the choices people make as they navigate their way around urban spaces has been an intrinsic part of the transport-studies-orientated research that informs urban policy. However, despite well-documented critiques of these approaches (see, for example, Kenyon and Lyons, 2003), much urban and transport policy remains based on a series of assumptions relating to predefined journeys informed by rational decision making. This paper draws upon research conducted on everyday urban walking as a means of reconceptualising decision-making processes beyond those whereby decisions are considered as being made at a specific time and place somehow outside the practice of walking. It is argued that in understanding decision making in the context of everyday mobility within urban and transport policy it is instead important to focus on notions of habit and routine.

Focusing on habits and habitual behaviour as opposed to individual travel choices being "driven (solely) by economic optimization" (Lyons, 2004, page 492) is far from new within transport studies and research (see, for example, Banister, 1978; Kenyon and Lyons, 2003; Verplanken et al, 1994; 1997). However, the type of transport research that is drawn upon by policy has a tendency to adopt reductive conceptualisations of habit whereby habit is an external force that somehow drives human behaviour. Furthermore, in much of this transport research habit is frequently positioned as prohibitinginformed decision making. For example, studies on transport-mode choice 
often draw upon models from social and behavioural psychology in which habit is understood as a causal variable in car reliance (see, for example, Fujii and Kitamura, 2003). The imperative is then to 'defrost' these habits in order for people to establish more sustainable travel behaviour. In contrast, beyond the transport arena, habit has been constructed as 'productive', 'beneficial', and 'economic' in saving cognitive effort which in turn results in positive outcomes [see, for example, Kahneman (2003) on the productivity of habits]. The potential, as opposed to constraining, dimensions of habit also extend to a rich array of writings across philosophy and the social sciences in which, rather than an external force driving behaviour, habit is considered in relation to emergent, unfixed, and ongoing processes and practices. On the one hand, there is a well-established (yet increasingly attracting renewed attention) body of work that seeks to unpack and develop the theoretical nuances of notions of habit and the habitual (see, for example, Bourdieu, 1977; Merleau-Ponty, 2002; Ravaisson, 2008). However, much of this theoretical writing on habit and practice is highly abstract and the question often remains as to how we empirically research and account for the space-times of habits and routinised behaviours. Theories of social practice also seek to understand everyday habitual behaviour (Reckwitz, 2002; Schatzki, 1996), often in the context of empirical concerns, ranging from everyday sustainable consumption patterns (Shove, 2005) to seasonality and urban office workers (Hitchings, 2010a). Rather than drawing a distinction between these bodies of work, this paper seeks to explore how various modes of theoretical engagement with habitual behaviours and routines can translate into something meaningful for transport practitioners and policy makers. These issues are addressed by pulling together transport policy concerns with decision making with theoretical writings on habit and routine into a productive dialogue.

The paper explores the significance of habitual decision making to engaging with the complexities of urban walking in the context of data collected as part of a broader project on walking in the city. The paper starts by arguing that, although there is much work on habitual behaviour within transport research, walking policy continues to focus on other motivations and barriers to walking such as health and environmental ones, whilst transport research that focuses on the role of habit in travel choices is concerned primarily with the individual. The paper moves on to explore growing concerns in understanding sustainable transport, such as walking and cycling, in relation to the coordination of people's everyday lives where the household becomes the unit of analysis for understanding travel behaviour. Interview and diary data are drawn upon to illustrate how decisions to walk are not only made up of factors relating to the built environment or people's health, as frequently considered in the policy arena, but need to also be understood as intimately bound up with people's day-to-day routines. It is argued that examining the relationship between pedestrian movement and daily-life coordination begins to reveal the complexity of how, and whether, people walk. The interview and diary data also make visible the multiple dimensions that feature in people's day-to-day lives, thus revealing the significance of how walking fits within these coordination activities. However, the final part of the paper draws attention to the importance of considering the processual and experiential dimensions of walking, and the ways in which journeys into, and through, the city unfold. In so doing, it is argued that focusing on forms of habitual performance as opposed to plotting, mapping, or modeling habitual decision making, assists in engaging with everyday urban movements. Exploring the habits of everyday urban mobilities such as the daily commute not only highlights the complexity and ongoing reconfiguration of these journeys beyond analysis informed by rational intention but the way this form of engagement makes it possible to analyse the significance of how each part of the journey opens up into the next as a series of sequentially organised and occasioned events. 
Furthermore, the discussion of data illustrates the conceptual nuances concerning habit and routine and the importance of making an analytic distinction between them. The paper concludes by arguing that understanding habit as situated and part and parcel of the unfolding action of urban pedestrian movement enables the transformative potential of habitual walking behaviour to be realised. In other words, the current tendency of policy-informing transport research to conceive of habit as an external force that somehow obstructs more 'positive' sustainable travel behaviour, overlooks the potential of habit and routines in relation to how walking is understood and promoted. In acknowledging methodological concerns with how everyday routine behaviours are researched (see, for example, Hitchings, 2010a), consideration is given throughout the paper to specific narratives of everyday urban mobilities; the significance of how such practices are actually 'talked about'; and how these accounts matter in engaging with the experiential dimensions of urban movement. This discussion critically examines how empirical work on everyday habit and routine is undertaken and how understandings of habit enable decision-making processes to be reconceptualised in the context of everyday urban mobility.

\section{Research context}

The last ten years have seen sustainable modes of transport such as walking and cycling become key UK transport policy issues. This is particularly evident in London where a growing population continues to contribute to increased road congestion. In addition to encouraging people to use public, as opposed to private, transport, walking has been positioned as an integral part of London's regeneration strategy. For example, in 2001 The Mayor's Transport Strategy proposed to make "London a prosperous city by: supporting sustainable economic growth by tackling congestion and unreliability, providing improved access to public transport, walking and cycling" (GLA, 2001, page 61). In A Walking Strategy for Central London, the Central London Partnership (CLP, 2001) also outlined what they considered to be the benefits of moving on foot, which include it being a healthy and sustainable transport mode that benefits "the community" and is "good" for "business". In 2004 a series of policy documents were published that coincided with the launch of the first national Walking and Cycling: An Action Plan (DfT, 2004) and firmly positioned walking as a mode of transport considered "crucial for urban regeneration and economic vitality" in London (Transport 2000 Trust, 2003, page 3). In addition to studies commissioned by the Central London Partnership on both public space (Gehl Arichitects, 2004) and pedestrian accessibility (Intelligent Space, 2004) in central London, the Greater London Authority (GLA) produced the The London Plan (2004) and Transport for London (TfL) launched Making London a Walkable City: The Walking Plan for London (2004). The London walking plan was a product of the then Mayor, Ken Livingstone's, 'vision' to make London one of the world's most walking-friendly cities by 2015. The plan detailed the benefits of, and potential barriers to, walking. Its stated aim was to encourage walking and in so doing provide benefits which include "a greater use of public transport; a better environment; social inclusion; healthier lifestyles; an improved economy" (TfL, 2004, page 15). Sustainable transport, in the Capital continued to be a concern for the subsequent Mayor, Boris Johnson, with the introduction of schemes such as the Barclays-Bank-sponsored bike-hire scheme, nicknamed 'Boris's Bikes'. The most recent Mayor's Transport Strategy (GLA, 2010) also pays particular attention to the promotion of walking, with proposed measures including: "providing a safe, comfortable and attractive street environment" (page 197); "making it easier to plan journeys by foot" (page 198); and 'promoting the health and environmental benefits of walking" (page 199). 
However, despite these growing concerns with the promotion of pedestrian movement over the last decade in London, there still remains a lack of in-depth data on walking in the capital, with much walking policy informed by travel data such as the National Travel Survey (DfT, 2008; 2009) or localised pedestrian counts. TfL has made some attempts to engage with more in-depth understandings of walking with the commissioning of Gehl Architects to conduct a Public Spaces and Public Life study in London that details empirical findings from pedestrian counts and surveys from which recommendations are made surrounding public space and the urban pedestrian and cycling environment (Gehl Architects, 2004). More recently, TfL has commissioned research that focuses on walking behaviour, motivations, and barriers to pedestrian movement. However, much of this policy-commissioned research assumes that walking is a homogeneous and largely self-evident means of transport (Middleton, 2010). There is little attention paid to the experiential dimensions of walking. For example, what are the many different types, forms, and characteristics of urban walking? What does it mean to different people and how can we engage with the multiplicity of those experiences in a way that can translate into something meaningful for transport policy makers?

It was questions such as these that served as a departure point for the research discussed in this paper on urban walking in London. In particular, the study aimed to address a series of issues that included exploring the relationship between walking and built environment; the many different types, forms, and characteristics of walking; and the social dimensions of moving on foot. However, the overarching aim of the research was to focus on the experiential dimensions of urban walking and explore the significance of what actually happens between A and B as opposed to quantifying the frequency of pedestrian activities. The research took place across a transect through the inner London boroughs of Islington and Hackney. The transect cut through Barnsbury in Islington, then eastwards into Canonbury, through De Beauvoir Town and London Fields in Hackney. This transect was selected because of contrasts within, and across, each area in relation to the built environment and social concerns such as levels of wealth and deprivation (see Butler and Robson, 2003; Butler and Rustin, 1996). This allowed the walking experiences of different groups of people to be explored. A mixed-method approach was adopted that included a postal survey, experiential walking photo diaries, and in-depth interviews. This paper draws upon a range of diary and interview accounts produced by thirty-five participants detailing their urban walking experiences [see Middleton $(2009 ; 2010)$ for further discussion of the research setting and discursive analytic approach].

It is from this focus on pedestrian experiences that issues associated with decision making and everyday life coordination emerge as prominent concerns. There is a series of assumptions throughout the pedestrian policy documents or policy-commissioned reports mentioned above: if you get the built environment right, provide the right sort of information concerning wayfinding and the health and environmental benefits of walking, people will be encouraged to make more sustainable transport decisions to walk. Furthermore, the focus of much pedestrian policy is on predetermined decisions to walk or not as opposed to decisions that unfold throughout journeys on foot. The following discussion highlights that decisions to walk need to be understood not only in relation to the built environment but as habitual behaviour that is intimately bound up with people's everyday routines. Attention is drawn to the way these understandings assist in reconceptualising decision-making processes in the context of everyday urban mobilities such as walking. 


\section{Walking and the routine coordination of everyday life}

Concerns with notions of the everyday emerged in the 20th century from a body of literature whose aim was to bring to the fore people and things in the city that had previously been considered too banal or routine to be the focus of enquiry. Despite an overarching common concern with opening up new ways of reading and understanding the city, there is much variation in engagement with the realm of the everyday, from Lefebvre's (1995) concerns with the production of space to Habermas's (1992) writings on the public realm. However, it is de Certeau's (1984) focus on everyday walking practices that holds most relevance for the pedestrian decision-making practices being discussed here. As de Certeau develops his theory of everyday practices, he draws specific attention to the practice of urban walking. De Certeau was concerned with how everyday practices such as walking are tactically performed against the strategies of those in a perceived position of power such as planners, engineers, and architects. He suggests that pedestrian acts carry away and displace "the analytical, coherent proper meanings of urbanism" (page 102) whereby "the act of walking therefore becomes, in effect, one of the principal ways that citizens can refute the notions of moral and social order which have been inscribed on the landscape" (Hubbard, 2006, page 107). Highmore (2004) highlights that;

"the goal of the project for de Certeau "will be achieved if everyday practices

[such as walking], 'ways of operating' or doing things, no longer appear as merely the obscure background of social activity, and if a body of theoretical questions, methods, categories, and perspectives, by penetrating this obscurity, make it possible to articulate them' (de Certeau, 1984, page xi)" (page 317).

It is important to note that, despite being applauded for opening up such new ways of reading and understanding the city and bringing into view practical knowledges that have previously been neglected, there are various critiques of these everyday approaches and how the notion of the everyday has been engaged with (see, for example, Crang, 2000; Edensor, 1998, Simonsen, 2004; Thrift, 2000; 2004). However, in the context of the argument being presented in this paper, de Certeau's perspectives can be drawn upon as a means of acknowledging not only the significance of what actually happens between A and B on foot and the experiential dimensions of pedestrian practices, but that the space - times of decision making are within, and part and parcel of, these practices. Furthermore, in terms similar to those used by de Certeau to position walking as disrupting 'rational planning', the rational decision making of planners and policy makers is equally disrupted by this approach with notions of habit, routine, and repetition. Writings on the everyday draw attention to "the flow of repetitive experiences in space and time" (Vaiou and Lykogianni, 2006, page 733), but the question remains of how walking relates to these conceptualisations of everyday routines, habits, and repetitions. In other words, in what ways can notions of habit and routine be drawn upon as a more productive means of understanding decision making in the context of everyday mobile practices such as walking? As the previous section highlighted, the focus of pedestrian policy is very much on rational and individual decisions, barriers, and motivations to walking, particularly in relation to the built environment and issues concerning health and sustainable transport. However, the following discussion demonstrates that it is important to understand pedestrian movement and decision-making processes in relation to the coordination of people's everyday lives whereby the household becomes the unit of analysis for understanding travel behaviour.

In the Secret Lives of Cities Jarvis et al (2001) examine the relationship between everyday life and sustainable urban development. They used the concept of the "household lens" to argue that urban policy makers often overlook "the interconnection 
between household dynamics and urban structures" (page 74). The role that walking is taken to play in the coordination of many Islington and Hackney residents' daily routines reflects the links that Jarvis et al make between home, work, and movement when they point out that "the issues of commuting and transportation must be understood as one part of a more fundamental issue, that of coordinating everyday household life. This holistic view suggests that it is necessary to analyse this issue in a wider household context instead of a narrowly defined question of individual locations, distances, frequencies and modes of transport" (page 69). It can be argued that the following account is a reflection of the significance of understanding walking in these terms:

"Following trip to polling station started to make my way to work (again with husband, baby $+\operatorname{dog}$ ) stopping on the way for a coffee on Chapel Market. I had arranged for Solanta, our nanny, to meet us there. She had a cup of tea with us and took over with the baby and the dog. My husband and I then left for work, him by bike + me by foot" (diary-Gemma, Barnsbury resident, Islington).

Gemma's diary extract describes a recent journey to work. What the extract illustrates is that walking is a key resource in this household's morning routine. By the time they leave the coffee shop: part of the journey to work has been completed, the dog has been walked, childcare responsibilities have been handed over to the nanny, and the family have spent some time together. Whether to walk is not based on some preconceived decision relating to the built environment; instead walking is accounted for in terms of the coordination of their everyday routine [see Dowling (2000) and Schwanen (2011) on feminist perspectives of car use and the role of the car in managing complex daily routines].

The household is also a key focus of a recent interdisciplinary cross-institution Engineering and Physical Sciences Research Council (EPSRC)-funded collaboration on "Understanding Walking and Cycling". The overarching aim of the research is to unpack the complexity that has been identified in research on travel behaviour on how decisions are made to walk and cycle and to develop a 'toolkit' for planners and policy makers in order to deliver more effective policy measures. The starting premise of the project is that the "ways in which travel decisions are made remain poorly understood, especially in the context of complex and contingent household travel arrangements" (Jones et al, 2010, page 2), with preliminary outputs stressing the importance of understanding "the nature of travel behaviour and how it is embedded in communities and in everyday life" (Jones et al, 2009, page 10). However, this perspective can be argued to imply processes of rational decision making whereby decisions to walk are not only deliberate but somehow taken outside the practice of walking. This can in part be attributed to the research being theoretically underpinned by models from behavioural psychology such as the Theory of Planned Behaviour (Ajzen, 1991) and ecological models of walking and cycling behaviour which position a range of external factors, including individual, social, cultural, or organisational influences, as impacting upon, as opposed to being situated within, these mobile practices (see, for example, Saelens et al, 2003). In contrast, the following data extract illustrates the distributed nature of pedestrian decision-making practices and the complexity of how the journey to work may or may not be accomplished:

"Typical journey [to work] is bicycle door to door unless it's my turn or I have to take my son to nursery in which case it's a combined walk and bike ride. If the weather is good I put him on a bike seat on the back of the bicycle and I walk him because I don't like the traffic, even though I'm a seasoned cyclist I will not cycle him, he's only a year old, on the back. So I put him on the bike seat on the back of the bike, walk him to nursery which is about, round about a $12-15$ minute walk 
straight from the front door and once I've dropped him off I carry on cycling into work and then I reverse that on the way home" (interview-Ros, De Beauvoir Town resident, Hackney).

The reasons for walking in Ros's account are interpolated not only into the journey to work but also into the contingencies of whether or not it is Ros's turn to take her son to nursery. Walking is made a salient part of their journey in terms of a number of combinations. Her son becomes the bicycle's passenger as she pushes the bike; her journey on such days is a further hybrid of cycling and walking. In making visible those combinations she demonstrates that whether to walk or not, and assists the coordination of her daily routine of journeying to work but is occasioned within the household's responsibilities in relation to her son's nursery attendance. Sheller and Urry (2006) argue that transport research is misleading, as it tends "to examine simple categories of travel, such as commuting, leisure, or business as if these were separate and self-contained" (page 212). This is starting to change with increasing attention being paid to what people do during trips and a less rigorous separation of trips and stationary activities. However, the tendency is still prevalent, with a good example being the National Travel Survey data on walking in which "a trip is a one way course of travel having a single main purpose" and "walk trips are those where walking is the main mode in terms of distance" (DfT, 2007). Ros does not have a singular 'purpose of travel' for her 'trip on foot'; rather her movements involve the dual tasks both of getting her son to nursery and then continuing on to work on time. Hubbard (2006) also draws attention to the work of Jarvis et al when he points out that "negotiating the everyday city, and connecting our home and work lives, thus involves considerable skill and aptitude" and that "Jarvis et al (2001) insist that much of this practical accomplishment remains under examined by urban geographers" (page 114). Ros's account is a further reflection of the significance of understanding walking in these terms. However, are there other ways of thinking about accounts of walking patterns, such as those provided by Gemma and Ros, in the context of decision-making practices?

It is by turning our attention to theoretical notions of the 'home' that it becomes clear that more is at stake in resident's accounts of their pedestrian movements, as the following diary extract illustrates:

"Several times/wk I walk my partner to work in the morning. This gives us time to be together having conversation in a way we don't get at home, where there is always something else to do. We have some of our best talks on our morning walks and often solve dilemmas or come up with creative ideas. We have a specific route we follow that avoids major roads \& avoids the canal (too much bicycle traffic in the a.m. - also it's too difficult for 2 people to walk side by side when cyclists come by)" (diary-Lindsey, London Fields, Hackney resident).

At one level, Lindsey's diary entry draws attention to the physical environmental factors that influence her and her partner's choice of walking route in the morning. However, the way the environmental barriers of major roads and bicycle traffic influence where and how Lindsey and her partner walk is also intrinsically linked to their being able to walk side by side and talk easily. Their decision to walk is not based on purely environmental factors but on how walking affords them time to interact in a way other modes of transport do not allow. For example, there is not the distraction or pressure of driving a car, or stationary presence of other passengers on a train or a bus. In their essay on "Notes on the art of walking", Ryave and Schenkien (1974) explore the practical accomplishment of "doing walking", with particular attention drawn to what it is to walk together:

"such activities as conversing, being available for conversation, touching, laughing, offering of offerables such as cigarettes or sweets, parting, and so on, are made 
relevant, and expectable, by the sheer fact of walking-together. That is, the fact of walking-together provides for the propriety and expectation of these activities" (page 272).

Lindsey's account engages with and reflects upon the importance of this dimension of walking to her pedestrian experiences. However, the account also highlights that walking is an important resource in their day-to-day routine. Amin and Thrift (2002) argue that "the everyday rhythms of domestic life have rarely counted as part of the urban" in what they describe as "big picture" urban theory despite these "rhythms of the home" being a large part of city life that "need incorporating into an everyday sociology of the city" (page 18). Lindsey's extract is illustrative of the significance of domestic arrangements in terms of how they influence and play out in urban walking patterns.

The notion of 'home' cuts across many areas of geographical enquiry, the social sciences (see Blunt and Dowling, 2006), and particularly in work on the everyday. For example, Rankin (2003), Dyck (2005), and Dyck and McLaren (2004) emphasise that feminist geographers have long attempted to represent the "materiality of "the everyday" (Dyck, 2005, page 234) through their work on the routine and taken-for-granted activity in homes, neighbourhoods, and communities. Ellegård and Vilhelmson (2004) also point to the significance of the 'home' in the way everyday activities are performed. They describe the 'home' as a "pocket of local order" that has a key role in the coordinating activities of household members. The above discussion of Lindsey's diary account illustrates in her terms how household issues, arrangements, and coordination activities flow, intrude, and emerge within, and out of, the walking 'voyage'. There has been other work that has considered how notions of 'home' and comfort extend into travel spaces [see, for example, Bissell (2010) and Watts (2008) on trains; Jain (forthcoming) on coaches; Laurier (2004), Laurier et al (2008) on cars]. However, to date, there has been little that considers everyday walking practices in such terms. The argument being presented here is that these dimensions of everyday mobility are also important for gaining a greater understanding of pedestrian practices. It is this perspective that not only makes visible the productiveness of examining walking practices in relation to the 'home' or household but how the decision-making practices associated with pedestrian movement might usefully be considered in relation to notions of the everyday.

Ehn and Lofgren (2010) focus on the "invisibility" of routine as they explore "the large undercurrent of routines, creating rhythms and temporalities in everyday life, rarely noticed or reflected upon" (page 99). In the context of train commuters in southern Sweden, O'Dell (2009) argues that it is important to focus not only on the significance of commuting in people's lives but on broader concerns relating to how we understand the routines that emerge in people's everyday lives. The significance of routines to everyday urban walking patterns is rarely engaged with in pedestrian policy, yet the discussion thus far has drawn attention to the importance of understanding decisions to walk in the context of these types of everyday household routines. However, it can be argued that there is more to decision making in the context of everyday urban mobilities such as walking than both the individual rational decision making that dominates pedestrian policy and the household everyday coordination activities discussed above. For example, what are the habitual aspects of walking and how do they contrast with pedestrian routines? Do pedestrian routines necessarily have to be habitual and what does labeling them as such do to them? Attention now turns to how engaging with notions of habit and the habitual allows decision-making processes to be reconceptualised in the context of everyday urban walking patterns. 


\section{Policy and theoretical engagements with habitual behaviour}

Habitual behaviour is increasingly being identified as a key dimension of understanding the ways in which people travel, particularly in relation to sustainable development agendas and how to encourage more sustainable travel behaviour. For example, Lyons (2004) stresses the importance of transport research, policy, and practice in forging stronger links between transport and society. In so doing he highlights that it is necessary "to consider factors that underlie and influence travel choice, behaviour, and ultimately patterns of travel and car use." Lyons stresses that "phenomena such as social norms and habitual behaviour challenge the notion that 'individuals' travel choices are driven (solely) by economic optimization" (page 492). However, within pedestrian policy, walking is framed primarily in relation to rational decisions concerning the built environment, sustainable transport, and health benefits. The few occasions where attention is drawn to habitual behaviour (see, for example, TfL, 2008), it is identified as a barrier to people adopting different modes of travel. This is more broadly reflective of some bodies of academic literature in which habits are positioned as 'barriers' to sustainable behaviour. For example, Prillwitz and Barr (2009) argue that "habitual behaviour quickens and simplifies acting for a person, but the outcome for others is maybe less beneficial or even disadvantageous than it would have been as a result of a deliberate decision process. For measures trying to influence individual travel decisions, habits are very obstructive" (page 3). Yet, can habitual behaviour be understood differently, particularly in relation to decision-making practices? For example, are there ways in which it can be considered in relation to its transformative potential as opposed to being positioned as some form of external barrier to more 'positive' forms of travel behaviour? Furthermore, much transport research informing policy has a tendency to focus on the individual in relation to habitual behaviour. For example, as Verplanken et al (1997) explore the role of habit in the process of information use in daily travel-mode choices, they argue that expectancy-value models "emphasize the deliberate character of individual decision making" (page 2). But, how does habitual decision making relate to household coordination of everyday life?

There is a long lineage of philosophical writings engaging with notions of habit and habitual experience that date back to Aristotle. One of the most influential thinkers on habit is Ravaisson (2008), whose work informed the writings of philosophers including Bergson, Deleuze, and Heidegger. Ravaisson is concerned with the dual logic of habit as mechanistic repetition but also the freedoms this engenders. His work blurs, and thus challenges, the mind-body dualisms within the writings of those such as Kant who find habit problematic. In challenging mechanistic understandings of habit as restrictive, Ravaisson's work explores the transformative potential of habit in relation to the way repetitive action makes movements become easier, which results in greater freedom. Habit is positioned as dynamic, involving a series of corporeal competencies that refine action over time. More recently, contemporary work, including geographical writings, has started to reengage with Ravaisson and the genealogy of thought that followed, in relation to habit. However, much of this theoretically sophisticated work is highly abstract and provides little sense of how these concerns can be empirically engaged with. For example, in the context of this paper, how might these writings connect to the contemporary concerns of practitioners and policy makers such as who walks and why?

In recent years there has also been a growing body of more empirically situated work that seeks to explore how habits and routines emerge and are sustained in everyday life in relation to theoretical notions of social practice. For example, Hitchings (2010b) examines the habitual behaviour that city office workers become engaged with in relation to spending increasing amounts of time in climatically controlled indoor environments. 
Shove's (2010) work examines approaches embedded in contemporary environmental policy in relation to social change. She refers to the dominant model as "the paradigm of $\mathrm{ABC}$ - attitude, behaviour, and choice" and in so doing draws attention to the limitations of such an approach to the challenges of climate change. Shove is particularly critical of some of the work of behavioural psychologists, such as Paul Stern, in relation to the way habit is conceptualised and drawn upon to explain situations that cannot be situated within the $\mathrm{ABC}$ model of behaviour:

"For Stern, as for other psychologists, the notions of habit provide a means of importing concepts of context, positioning this as a driver of behaviour in cases where volition and choice are evidently lacking. But if we take a step back, the idea that habits drive behaviour is really odd - implying, as it does, that habit is not itself behaviour but is, rather, some abstract factor bearing down upon the behaviours it directs" (page 1276).

Instead, in relation to the argument that Shove develops, habit needs to be situated in the context of social practices and the way "understanding social change is in essence a matter of understanding how practices evolve, how they capture and lose us, their carriers, and how systems and complexes of practices form and fragment" (page 1279). In the last decade the type of transport research that predominantly informs urban and transport policy has increasingly considered notions of habit as a means of explaining travel behaviour. However, despite the writings of those such as Lyons (2004) acknowledging that travel behaviour is far from rational and cost optimising, habit is conceived of as somehow outside mobile practices: "It appears that for a given journey an individual will have a primary and default means of travel predetermined through habit" (page 502). Habit is thus positioned as an external force somehow driving behaviour. As previously discussed, this is in part a consequence of conceptions of habit being drawn from particular strands of behavioural and social psychology.

Shove (2010) highlights that this conceptualisation of habit is also more broadly reflective of models and concepts of social change situated within contemporary environmental policy. The same argument thus holds for urban and transport policy. There is little transport research, policy, and practice that is informed by conceptions of habitual behaviour whereby habit is understood as unfolding, emergent, and situated within mobile practices as opposed to outside of them. Furthermore, there is little transport research that understands habit as a social process (Reckwitz, 2002) as opposed to being something that is located within the individual. The remainder of this paper addresses such a gap by exploring the productiveness of understanding everyday urban walking in relation to emergent and processual notions of habit as opposed to rational decision making or reductive conceptions of habit as somehow being an external force driving movement. Attention is drawn to the significance of how people talk about habit and how notions of habit and the habitual are used as resources in the framing of people's accounts of their everyday pedestrian practices. It is argued that these accounts demonstrate how people become aware of their habitual behaviour only when it is interrupted.

\section{Unfolding journeys, habits, and habitual behaviour}

Walking policy's construction of 'trips on foot' consists of mainly predefined journeys from A to B with little reference to how the destination comes to be reached and what happens in between these points. However, Hannam et al (2006) draw attention to the fact that "means of travel are not only ways of getting as quickly as possible from A to B. Each means provides different experiences, performances and affordances" (page 15). The following participant accounts provide a means of engaging with these 
experiences and performances in terms of what characterises people's movements, and how the various twists and turns of their journeys unfold. Brown and Laurier (2005) refer to this as the "unfolding action" and "emerging sequential sense-making of a journey" (page 6) as each stage of the journey unfolds and opens up into the next. This focus contrasts with transport policy whereby concerns with decision making relate primarily to predetermined decisions to walk or not as opposed to how pedestrian decisions unfold throughout journeys on foot. This London Fields resident was asked about her typical journey to work and whether she used the same route each day:

"yeah, yeah, I always walk, which takes about 25 or 30 minutes. It's so boring!

Because it's, I think the quickest route, just because I think it's automatic pilot, I think I just, just walk the route. I even usually walk in the rain but if, for example, you know we had those really icy times, when the streets like literally are an absolute hazard, that's probably the only time I've considered getting on a bus. I think the journey would take me about the same amount of time on a bus. You know I think it would take about half an hour at that time of day and it's just much more unpleasant, you know in really overcrowded public transport. And also the expense I suppose" (interview-Alice, London Fields resident, Hackney).

Alice's interview extract is just one example of many in which walking can be understood in terms of everyday routines discussed in the previous section. In this instance it is the routine of commuting to work that features in her account. Highmore (2004) is concerned with "experiential aspects of routine" (page 307) and states that "the daily commute to work is perhaps one of the most distinctive modern routines" and that "commuters often describe their lack of attention to the actuality of these journeys, undertaken it would seem, as if on autopilot" (page 310). This is certainly a concern in Alice's account of her "automatic pilot" journey to work on foot. However, more is at stake here. For, as Highmore also points out, "there is something ambiguous and problematic about routine ... what routine feels like, how it is experienced, is by no means clear ... because routine is not only dictated from above. We establish our daily routines to give our lives rhythm and predictability" (page 307). Yet there is something challenging not only in what routine feels like but also in the habits that emerge from everyday routines such as those articulated in Alice's account. How do routines become habitual, what does habit feel like, and how do we become aware of habitual movements on foot?

In his writings on embodiment, habit, and the everyday, Harrison (2000) draws attention to the work of Varela (1992) and how the example of a lost wallet is used to illustrate the experiential dimensions of habit. The reader is asked to imagine walking down the road when the realisation strikes and panic sets in that your wallet is missing. Harrison points out that there has been some form of interruption to the sequence: "relaxed readiness, a breakdown, a gap opens up, and then an emergent order takes place" (page 503). He goes on to suggest "that it is habit which surrounds such encounters and resolutions, and it is habit which is interrupted in intervals" (page 503). However, Hitchings (2010a) draws attention to certain methodological concerns in relation to the way everyday habitual behaviours are researched. In particular, the difficulties with conducting research through the medium of talk and some scholars/theoretical arguments suggesting it is "inappropriate" to talk to people about their practices because they will be unable to discuss the habitual" (page 288). In contrast, Hitchings argues that "being sure about this remains a matter of empirical investigation" (page 288) and seeks to explore through interview data how people are 'captured' by indoor practices that show little variation between different seasons. Hitchings explicitly asked research respondents about their habitual behaviour; yet what is interesting in the discussion of data in this paper is that participants were 
not asked directly about their habitual walking behaviour yet frequently framed their understandings of everyday urban walking in such terms. In other words, notions of habit are drawn upon to articulate their everyday experiences on foot as opposed to these being shaped and informed by a series of rational decisions. For example, Alice not only makes relevant both practical knowledge relating to her everyday routine, such as knowing the quickest route on foot and the length of the bus journey, she also demonstrates the relevance to her of forms of 'embodied habits' in terms of walking on "autopilot" and the hazards associated with the icy streets. It would be possible to conceive of the 'icy times' she makes reference to as a similar 'interruption' to her habitual movements on foot to that of the lost wallet cited by Harrison. Both habit and how people become aware of habit are claimed as experienced in Alice's account. It is through this focus on the discursive organisation of participants' accounts (see, for example, Edwards, 1997; Potter, 2004) that we not only continue to see the significance of how habit is actually talked about but how people become aware of their habitual pedestrian behaviour when it is interrupted.

The following diary extract also illustrates the unfolding, sequential nature of walking:

"Regardless, I approach Northampton Road. Usually this is an unpleasant part of the walk. Often gangs of kids hang around in the park on either side riding oversized bikes into pedestrians too slow to get out of the way. One evening, as I passed, I remember a couple of lads setting off fireworks and letting them shoot across the path as pedestrians dodged, ducked, dipped, dived and dodged. I said a large part of walking is about dodging things. But today those coming the other way are a couple with a pushchair. These two, coupled with the smell of a freshly rained upon London make this part pleasant today and I enjoy the walk. I also enjoy the next thing that happens. A cyclist makes a special effort to stop before a zebra crossing to let me cross. Unexpected, but welcome" (diary_Paul, Canonbury resident, Islington).

The fireworks going off on the path, the couple with the pushchair, and the cyclist who stops can be taken to exemplify this occasioned unfolding of walking in Paul's account. However, Paul's diary entry is itself organised in terms of the unfolding and sequentially organised features of his experience, both of his habitual walking patterns (in terms of what he is reminded of) and in relation to the salience to him of his walking on a particular day. In addition, his account does far more than identify the habitual nature of movement he engages in as an urban walker. His accounting is also organised in terms of the unfolding sensuality of walking. The entry is framed in terms of the contrast between what is "usually ... an unpleasant part of the walk" with experiences that remediate his habitual sense of that "part" in his walk (the unexpected presence of others and their courtesy, smells, his enjoyment). Furthermore, despite taking the same route to and from work each day and the occasioning of the diary entry in relation to 'typicality' or his habitual pedestrian experiences ("Usually this is an unpleasant part of the walk"), his examples also illustrate the way people become aware of habit when it is interrupted. For example, engaging with notions of the everyday, and what Edensor (2002) describes as "habitual performances", reveals important features of the significance of Paul's account. Paul makes multiple references to "embodied habits" (page 94), or practical, embodied knowledge, relating to particular and appropriate ways of walking. The pedestrians who are too slow to get out of the way of the fireworks, walking being about physically "dodging things", and the cyclist stopping to let him cross the road are all examples of interruptions that make Paul aware of these embodied habits.

Interview participants' responses were also organised in terms of contrasts between the generalities and particularities of the contingent, unfolding organisation of walking. 
One way in which they accomplished this was to talk in hypothetical terms rather than giving specific examples that relate to their experiential performances of moving on foot. For example, this Barnsbury resident describes how she would imagine she would react in the following scenarios:

"If I was setting off down, setting off down Barnsbury Road to walk to St Johns Street and the 153 bus kind of came round the corner, I, I don't know if it had happened to me but I would imagine that I would easily be tempted to stick my hand out. And then the other times if I was there and I just got impatient or felt energetic I'd just think 'oh hell I'll walk', you know if it didn't arrive immediately" (interview-Christine, Barnsbury resident, Islington).

Christine sets up her account as an imagined journey; "I don't know if it had happened to me but I would imagine that I would". She describes how she imagines she would react if she was setting off to walk and her bus came round the corner or if she was getting impatient waiting for her bus. Of what use is an imagined account in developing an understanding of urban pedestrian movement in contrast to one oriented to the particularities of experience? Despite constructing a generalised imagined account, Christine is able to achieve this only by drawing upon the particularities of her local knowledge emerging from her habitual pedestrian behaviour. In Edensor's (2002) terms, Christine's imagined account of her local movements on foot is occasioned in terms of her everyday "popular competencies". As she points out that she doesn't know "if it had happened to me", this can be argued as being illustrative of Edensor's further point that "these everyday forms of practical knowledge are rarely the subject of any reflection, for they constitute part of the normal competencies required to sustain a livelihood and a social life" (page 93). However, despite rarely being a "subject of any reflection" what the above interview extract continues to demonstrate is how participants frame their accounts of walking in relation to habits and routines with people becoming aware of 'popular competencies' emerging from habitual behaviour when these are interrupted.

This London Fields resident was asked to explain the differences he experiences when walking in the city compared with walking in the countryside:

"I think when you're hill walking you're, you can concentrate on different things, when you're in the urban environment you're always going to have, you certainly have to watch out for traffic and what's going on around you much more, you have to have your wits around you a bit more. Er, whereas when you're hill walking you have to watch your feet because it's uneven but um, you know other than that you can just enjoy what's around you but on a road you have to keep an eye out for traffic and other potential hazards" (interview-Alan, London Fields resident, Hackney). Alan draws attention to the way the variations between the sensual dimensions of walking in the city and the countryside emerge in terms of how movement is already in relation to different things and contexts. For example, the account points to the importance of vision in avoiding traffic in the city on foot, whereas "you have to watch your feet because it's uneven [ground]" when hill walking. What it is to "watch your feet' is qualitatively different from what it is to 'watch out for traffic' where sight and sound matter. Watching your feet also raises the salience of touch when negotiating and feeling for the uneven terrain of the rural environment [see also Edensor (2000), Ingold (2004), Labelle (2008), and Middleton (2010) on embodied pedestrian experiences]. However, what Alan's account also highlights are the challenges of urban walking and that he considers you "have to have your wits around you" when walking in the city. As Lefebvre (2004) attempts to 'grasp' understandings of urban rhythms within his broader rhythmanalysis project, he considers the rhythms of the urban walker through observations made from a balcony overlooking the streets of Paris: 
"Towards the right, below, a traffic light. On red, cars at a standstill, the pedestrians cross, feeble murmurings, footsteps, confused voices. One does not chatter while crossing a dangerous junction under the threat of wild cats and elephants ready to charge forward, taxis, buses, lorries, various cars" (page 28).

These observations align with aspects of urban walking that Alan makes relevant in his account concerning having "to watch out for traffic and what's going on around you much more." Lefebvre contrasts his observations from the window of the urban rhythms emerging below him with "he who walks down the street" who is "immersed in the multiplicity of noises, murmurs, rhythms" (page 28). In so doing, Lefebvre poses the question of the extent to which the urban walker pays attention "except at the moment of crossing the street, when he has to calculate roughly the number of his steps" (page 28). As noted elsewhere (see Middleton, 2009), despite providing a theoretical departure point, Lefebvre provides little sense of how we might empirically engage with these theoretical concerns. Therefore, in the context of the data being discussed in this paper, we might consider concerns with pedestrian concentration and levels of awareness made relevant both by the theoretical writings of Lefebvre and by the urban pedestrian experiences of those research participants such as Alan. For example, how do the challenges of urban walking identified above relate to notions of habit, habitual behaviour, and associated decision-making practices? And in what ways do automated movements on foot hinder or assist people negotiating the urban environment on foot?

\section{The transformative potential of habit}

In writings on pedestrians in the context of automobile growth in the interwar period in London, Hornsey (2010) draws particular attention to government and policy attempts to regulate and automate pedestrian movement. He highlights that Taylorism was at the heart of instilling urban pedestrians with correct and automated corporeal habits due to them being considered "prone to distraction and absent-mindedness" (page 106) that contributed to a growing number of accidents and fatalities. Measures such as guardrails and designated pedestrian crossings were introduced with varying success rates as a means "to automate pedestrians and recodify their practices as a disciplined set of habituated responses" (page 111). The limited success was in large part due to the complexity of London's street network coupled with the need for a more nuanced engagement with predicting walking behaviour. Hornsey concludes that "pedestrian behaviour became less about habituating certain corporeal actions, than about instilling a type of intelligent responsiveness that could readily adapt to all unforeseen circumstances" (page 111). In returning to Paul's diary we can begin to understand not only how habitual actions emerge from pedestrian practices themselves rather than something imposed upon urban walkers, but how habitual behaviour is a means for coping with the challenges of negotiating the city on foot:

"This time last week I had just come back from holiday and my traffic light awareness function was not quite operating at its optimal capacity. You get a sense of timing when doing the same route each day. Where to cross and lose least time. Which corners are blind and make the heart race. And which order the traffic lights change in so you're one pace ahead of the infrequent walkers.

Last week my timing was all over the place - now I'm back, a fact brought to my attention as Toby runs to follow me across the road. Point to note: I never run across the roads. It's just not dignified" (diary - Paul, Canonbury resident, Islington).

Paul's diary entry draws attention to his "sense of timing" and the durational qualities of his journey on foot in relation to the way time expands and contracts [see Middleton (2009) for more detailed discussion on time, space and rhythm in 
relation to urban walking]. Paul's diary entry is framed around what he terms his "traffic light awareness function" and how it was not working to its "optimal capacity" after he returned from holidays. Paul moves on to qualify the features of this "awareness function" in relation to knowledge of where to cross the road and the order of traffic lights in order to increase the efficiency of his movements. All of this relates to what he positions as a "sense of timing" which emerges from the routine of his daily walk to work. Paul emphasises the significance of these dimensions of his pedestrian experiences by contrasting the pace of his movements on foot with those of "infrequent walkers". However, there is more at stake in Paul's diary entry than the speed and efficiency of his routine journey to work. Paul's account also makes relevant the significance of habitual behaviour for the way we understand decision-making processes in the context of urban walking.

Paul's focus on his "sense of timing" illustrates that journeys on foot have less to do with a series of rational decisions taken outside pedestrian practices as conceived in transport policy than relate to a series of unfolding habitual movements. As Lefebvre (2004) notes in relation to the notion of bodily dressage, "One breaks-in another human living being by making them repeat a certain act a certain gesture or movement" (page 39). Paul's diary entry illustrates that repetition is not only key to the unfolding flow of his walk to walk but also to his competency as an urban pedestrian. Paul emphasises this competency that emerges from his habitual movements not only by contrasting it with the "infrequent walkers" and his friend Toby's "undignified" dash across the road but with his own movements the previous week when he had just returned from holiday and his "timing was all over the place". Whilst these features of his diary entry illustrate the way walking routines transform over time, they also highlight the significance of maintaining the repetition of movements on foot for walking routines to become habitual. In other words, walking routines are not necessarily habitual routines. This is a significant conceptual point as it emphasises the importance of making an analytic distinction between conceptions of habit and notions of routine.

In Seamon's (1980) writings on a phenomenology of everyday life, he proposes an understanding of 'bodily intentionality' called "body-subject":

"Body-subject is the inherent capacity of the body to direct behaviours of the person intelligently, and thus function as a special kind of subject which expresses itself in a preconscious way usually described by such words as 'automatic,' 'habitual,' 'involuntary,' and 'mechanical'" (page 155).

For, as Hubbard (2006) elaborates, "the implication here is that we do not have to think about the way we move through urban space: our body feels its way" (page 119). Seamon (1980) expands upon his notion of the "body-subject" with "body-ballets" where "basic movements of body-subject fuse together into wider bodily patterns that provide a particular end or need" (page 158) and "time-space routines" which are "a set of habitual bodily behaviours which extends through a considerable portion of time" (page 158). Seamon's notion of "place ballets" denotes how integrated sets of embodied gestures, behaviours, and task-oriented actions of individuals combine into dynamic wholes that become important places of interpersonal and communal exchanges, actions, and meanings. Paul's account illustrates the significance of place ballets to walking practices and experiences in relation to affording a sense of being in place. One of the affordances of habits is that they facilitate this synchronicity.

Various writings draw attention to the way people cope with the challenges of urban life. For example, Simmel (1971) focuses on the way the body can be conceived of as shutting down to cope with the sensory overload of urban life. In similar terms, Bull $(2000 ; 2005)$ explores the use of Walkmans and I Pods as a means by which people 
manage everyday urban life. Paul's account is one of several examples whereby urban walkers rely on their habitual movements as a strategy for coping with the challenges of negotiating the city on foot. This is turn demonstrates the transformative potential of habit as opposed to the restrictive ways in which it is understood within much transport research and policy previously discussed. This transformative potential emerges from Paul's habitual movements that enable him to be 'in synch' with his environment. In line with Ravaisson's (2008) focus on the dual logic of habit, movement becomes effortless and receptivity declines, whilst simultaneously, spontaneity increases and a space-time emerges which allows a focusing of attention on other concerns. In the context of urban walking, these concerns might include concentrating on maximum efficiency, minimising a perceived loss of time, or getting to the destination as quickly as possible. Yet of what wider significance are these and the broader issues raised in this paper, particularly in relation to decision-making practices and the way urban walking is engaged with and promoted in the policy arena?

\section{Conclusion}

Much policy-commissioned and transport research assumes that walking is a homogeneous and largely self-evident means of transport (Middleton, 2010). Little attention is paid to the experiential dimensions of moving on foot. In contrast, this paper, and the wider research upon which it is based, has sought to focus on the experiential dimensions of urban walking and in so doing explore the significance of what actually happens between A and B as opposed to quantifying the frequency of pedestrian activities whilst assuming all of these journeys to be the same. It is through focusing on these pedestrian experiences that issues associated with decision-making practices emerge as key concerns for understanding the complexity of urban pedestrian movement. In exploring the decision-making processes associated with everyday urban walking, the argument has been made that it is important to focus on notions of habit as opposed to forms of rational decision making that characterise much urban and transport policy. Furthermore, as opposed to reductive conceptualisations of habitual behaviour within transport research, whereby habit is positioned as an obstructive, external force driving individual behaviour, attention has been drawn to the fact that habit needs to be understood as situated in the processual and unfolding action of journeys on foot. Whilst acknowledging methodological concerns relating to the inappropriateness of the medium of talk for researching routine and habitual practices, attention has been drawn to the significance of how habits are actually 'talked about'. Despite participants not being directly asked about their habitual walking behaviour, understandings of everyday urban walking are frequently framed in such terms. Notions of habit are drawn upon as resources for how people frame their everyday experiences on foot as opposed to being shaped and informed by processes of rational decision making. This focus on the discursive organisation of participant's accounts therefore highlights the significance of the medium of talk for how habitual behaviour is researched.

Throughout this paper transport policy concerns with everyday urban mobility and decision making have been drawn together with theoretical writings on habit and routine. Clear policy contributions unfold from this dialogue in relation to these emergent understandings of habitual behaviour in terms of how urban walking is promoted. Although the transferability of research findings can never be assumed, given that the processes and situations discussed by respondents concerning everyday walking practices are not unique to London, it is reasonable to conclude that the findings regarding pedestrian routines and habits also pertain to other Western cities where walking is a reasonably significant mode of transport. One set of insights 
relates to the way habit and habitual behaviour are conceptualised. Several features of participant's accounts have illustrated how walking routines transform over time and that it is the maintenance of these routines that makes them become habitual. It is possible to have multiple walking routines, yet the movements that unfold from these routines are not necessarily habitual. Therefore there is an analytic distinction to make between notions of habit and routine. This is significant in policy terms in relation to frequent and infrequent walking. In current transport and pedestrian policy much walking is treated in the same way with pedestrian movement largely considered a homogeneous mode of transport. Although walking measures have been targeted at different social groups such as young people (TfL, 2008), commuters (Living Streets, 2011), and professional women (Islington Council, 2007), less attention has been paid to the different types and forms of walking which unfold throughout these different journeys on foot.

As the data discussed have highlighted, walking in the city can be a challenging experience and requires a certain level of competency that, in contrast to cycling, is often neglected in urban and transport policy discussions. The argument presented in this paper has illustrated the way in which habitual movements are a coping mechanism for pedestrians as they negotiate the city on foot. As habitual behaviour emerges from the everyday practices of urban pedestrians it facilitates both a decline in receptivity and an increase in spontaneity that are able to assist the ease with which pedestrians negotiate urban space. A focus on habit, as opposed to rational decision making, and how walking routines become habitual through the practices of frequent walkers would enable policymakers to gain a greater understanding of the nuances of what it is to become a skilled and accomplished pedestrian. This in turn would mean walking measures could be targeted more appropriately at facilitating the ways in which these habitual behaviours emerge with ease in the everyday practices of infrequent pedestrians. For example, pedestrian policy currently pays little attention to footwear, clothing, or luggage, or what could be termed 'walking attire'. This absence is in direct contrast to the broader research upon which this paper is based whereby the salience emerged of material objects in participants' movements on foot and the coagency of these "mundane technologies" in assemblages of urban walking practices (Middleton, 2010). Although material objects (such as footwear, clothing, mobile technologies, luggage, and the transportation of personal effects), could be considered mundane features of everyday life they really do matter in the everyday experiences of urban pedestrians. These are all items that have the potential to 'equip' or 'encumber' pedestrian practices that in turn strongly relate to the ease within which habitual behaviour emerges and is sustained. Furthermore, exploring the role of "mediating mundane technologies" (Michael, 2000) to walking practices, highlights to policy makers the significance of materialities beyond the built environment and hard city infrastructures (such as pavements and pedestrian crossings) which form the dominant focus of current pedestrian policy documents.

Deleuze (2001) contends that habits are ways of being. We do not have habits that exist independently, instead we are nothing but habits. It is conceiving of habit as situated within the ongoing reconfiguration of journeys on foot that makes visible its transformative potential as opposed to the restrictive associations preventing more 'positive' and sustainable travel behaviour that feature in much transport research. A focusing on the transformative potential of habitual behaviour, in relation to theoretical writings on habit identified in the context of the data discussed here, also has a series of policy implications for the promotion of walking in the city. Elsewhere attention has been drawn to the fact that walking allows so much more than transportation (Middleton, 2009). In particular, an understanding of how people's sense 
of time expands and contracts as they walk opens up the possibility of doing other parallel activities such as talking on the phone, spending time with family members or friends, or planning the work day ahead in ways that other forms of transport are unable to do. A large part of how these activities are able to take place is in relation to the habitual unfolding of journeys on foot. In other words, the habits and routines that emerge through pedestrian practices make other activities possible. Furthermore, they also make rationality possible as it is conventionally understood in transport policy and research discourses, whereby being rational is equated to minimising travel time and travel effort (see Bannister, 2011; Mokhtarian, 2005). It is a focus on these habitual dimensions of everyday walking, as opposed to rational decision making, that highlights the ways in which journeys on foot might be promoted within urban and pedestrian policy. For example, rather than emphasising the health and environmental benefits of pedestrian movement underpinned by rationally informed decisions somehow taken outside pedestrian practices, walking should be promoted more widely in relation to its underappreciated dimensions such as how it resources family life or is a key function in maintaining social relationships. This will involve transport planning and research reconceptualising habitual behaviour not as negative and obstructive but as opening up and enabling a range of possibilities. In addition, it is this perspective which draws attention to the need for pedestrian policy to focus not only on predetermined decision making as whether to walk or not but on the significance of how decisions unfold throughout any given journey on foot.

It is also possible to conceive of notions of habit and routine in more positive ways in the context of everyday urban walking in relation to the built environment. Much of the discussion of data in this paper has drawn attention to the way many journeys on foot unfold as if pedestrians were on 'autopilot'. Writings within social and cultural theory have long engaged with how the body moves in these ways (see Lefebvre, 2004; Simmel, 1971). However, this is also significant in urban and pedestrian policy terms. For example, an area might be considered more 'walkable' if the flow of pedestrian movement could seamlessly flow on 'autopilot' (Middleton, 2010). It is habitual behaviour that facilitates such movement. Pedestrian policy makers might do well not only to acknowledge the significance of habitual behaviour as opposed to rational decision making in how urban walking is understood and promoted but, unlike much transport research, to conceive of habit in ways other than it being an obstructive, external force preventing more sustainable travel behaviour. It is through such measures that further steps will be taken towards understanding the complexity of urban walking and promoting it more effectively.

Acknowledgements. This research was made possible by doctoral and postdoctoral support from the ESRC (PTA-033-2003-00014 and PTA-026-27-1500). Many thanks to Tim Schwanen, Derek McCormack, and Gordon L Clark for organising the "Rethinking the space-times of decision making" session at the Association of American Geographers Conference, Washington, DC in 2010 at which a version of this paper was first presented. Thanks also to David Bissell, David Middleton, Tim Schwanen, and three anonymous referees for their constructive and helpful comments and feedback.

\section{References}

Ajzen I, 1991, "The theory of planned behaviour" Organisational Behaviour and Human Decision Processes 50179 - 211

Amin A, Thrift N, 2002 Cities: Reimagining the Urban (Polity Press, Cambridge)

Banister D, 1978, "The influence of habit formation on modal choice-a heuristic model" Transportation 75 - 33

Bannister D, 2011, "The trilogy of distance, speed and time" Journal of Transport Geography $19950-959$ 
Bissell D, 2010, "Passenger mobilities: affective atmospheres and the sociality of public transport" Environment and Planning D: Society and Space $28270-289$

Blunt A, Dowling R, 2006 Home (Routledge, London)

Bourdieu P, 1977 Outline of a Theory of Practice (Cambridge University Press, Cambridge)

Brown B, Laurier E, 2005, "Maps and journeys: an ethnomethodological investigation" Cartographica 4(3) $17-33$

Bull M, 2000 Sounding Out the City: Personal Stereos and the Management of Everyday Life (Berg, Oxford)

Bull M, 2005, "No dead air! The iPod and the culture of mobile listening" Leisure Studies $\mathbf{2 4}$ $343-355$

Butler T, Robson G, 2003 London Calling: The Middle Classes and the Re-making of Inner London (Berg, Oxford)

Butler T, Rustin M, 1996 Rising in the East?: The Regeneration of East London (Lawrence and Wishart, London)

CLP, 2001 A Walking Strategy for Central London Central London Partnership, London

Crang M, 2000, "Relics, places and unwritten geographies in the work of Michel de Certeau", in Thinking Space Eds M Crang, N Thrift (Routledge, London) pp 136-153

de Certeau M, 1984 The Practice of Everyday Life (University of California Press, Berkeley, CA)

Deleuze G, 2001 Difference and Repetition translated by P Patton (Continuum, London)

Df T, Department for Transport, London 2004 Walking and Cycling: An Action Plan (The Stationery Office, London)

2007 Walking: Personal Travel Factsheet (January), http://www.dft.gov.uk/pgr/statistics/ recentforthcoming publications/recentpublications 2008 National Travel Survey: 2007 (The Stationery Office, London) 2009 National Travel Survey: 2008 (The Stationery Office, London)

Dowling R, 2000, "Cultures of mothering and car use in suburban Sydney: a preliminary investigation" Geoforum 31345 - 353

Dyck I, 2005, "Feminist geography, the 'everyday' and local-global relations: hidden spaces of place-making" The Canadian Geographer 49233 -243

Dyck I, McLaren A T, 2004, "Telling it like it is? Constructing accounts of settlement with immigrant and refugee women in Canada" Gender, Place and Culture $11513-534$

Edensor T, 1998 Tourists at the Taj: Performance and Meaning at a Symbolic Site (Routledge, London)

Edensor T, 2000, "Walking in the British countryside" Body and Society 6(3/4) 81-106

Edensor T, 2002 National Identity, Popular Culture and Everyday Life (Berg, Oxford)

Edwards D, 1997 Discourse and Cognition (Sage, London)

Ehn E, Lofgren O, 2010, "Routines - made and unmade", in Time, Consumption and Everyday Life: Practice, Materiality and Culture Eds E Shove, F Trentmann, R Wilk (Berg, Oxford) pp 99-114

Ellegård K, Vilhelmson B, 2004, "Home as a pocket of local order: everyday activities and the friction of distance" Geografiska Annaler, Series B: Human Geography 86281 - 296

Fujii S, Kitamura R, 2003, "What does a one-month free bus ticket do to habitual drivers? An experimental analysis of habit and attitude change" Transportation 3081 -95

Gehl Architects, 2004 Towards a Fine City for People: Public Spaces and Public Life-London Gehl Architects, Central London Partnership, Transport for London, London

GLA, Greater London Authority 2001 The Mayor's Transport Strategy 2004 The London Plan: Spatial Development Strategy for Greater London 2010 The Mayor's Transport Strategy

Habermas J, 1992 The Structural Transformation of the Public Sphere: An Inquiry into a Category of Bourgeois Society (MIT Press, Cambridge, MA)

Hannam K, Sheller M, Urry J, 2006, "Editorial: Mobilities, immobilities and moorings" Mobilities $11-22$

Harrison P, 2000, "Making sense: embodiment and the sensibilities of the everyday" Environment and Planning D: Society and Space $18497-517$

Highmore B, 2004, "Homework: routine, social aesthetics and the ambiguity of everyday life" Cultural Studies 18306 - 327

Hitchings R, 2010a, "Seasonal climate change and the indoor city worker" Transactions of the Institute of British Geographers, New Series $35282-298$

Hitchings R, 2010b, "Urban greenspace from the inside out: an argument for the approach and a study with city workers" Geoforum $41855-864$ 
Hornsey R, 2010, “'He who thinks, in modern traffic, is lost': automation and the pedestrian rhythms of interwar London", in Geographies of Rhythm Ed. T Edensor (Ashgate, Farnham, Surrey) pp $99-112$

Hubbard P, 2006 City (Routledge, London)

Ingold T, 2004, "Culture on the ground: the world perceived through the feet" Journal of Material Culture $9315-340$

Intelligent Space, 2004 London's Functional Walking Network http://www.intelligentspace.com/ projects/10133.htm

Islington Council, 2007 Walk Islington: Explore the Unexpected Islington Council, London

Jain J, forthcoming, "The classy coach commute" Journal of Transport Geography

Jarvis H, Pratt A C, Wu P C C, 2001 Secret Lives of Cities (Prentice Hall, Harlow, Essex)

Jones T, Harwatt H, Horton D, Jopson A, Pooley C, Scheldeman G, Tight M, 2009, "Understanding walking and cycling: a multi-method approach to investigating household decision making in relation to short journeys in urban areas", paper presented at Cycling and Society Research Group Symposium, University of Bolton, 7 September, http://www.lec.lancs.ac.uk/research/ society_and_environment/cycling/CSRG_6th_Symposium_Tim_Jones_UWAC_070909.pdf

Jones T, Pooley C, Chisholm A, Horton D, Scheldeman G, 2010, "Understanding walking and cycling: interim findings from a multi-method approach to investigate household decisionmaking in relation to short journeys in urban areas", paper presented at 12th World Conference on Transport Research, Lisbon, 11 - 15 July, http://www.lec.lancs.ac.uk/research/society_and _environment/cycling/WCTR_TJ_July_2010.pdf

Kahneman D, 2003, "Maps of bounded rationality: psychology for behavioral economics" The American Economic Review 931449 - 1475

Kenyon S, Lyons G, 2003, “The value of integrated multimodal information and its potential contribution to modal change" Transportation Research Part F-Traffic Psychology and Behaviour $5267-287$

Labelle B, 2008, "Pump up the bass: rhythm, cars and auditory scaffolding" The Senses and Society $3187-203$

Laurier E, 2004, "Doing office work on the motorway" Theory, Culture and Society 21261 - 277

Laurier E, Lorimer H, Brown B, Jones O, Juhlin O, Noble A, Perry M, Pica D, Sormani P, Strebel I, Swan L, Taylor A S, Watts L, Weilenmann A, 2008, "Driving and passengering: notes on the ordinary organisation of car travel" Mobilities $31-23$

Lefebvre H, 1995 The Production of Space (Blackwell, Oxford)

Lefebvre H, 2004 Rhythmanalysis: Space, Time and Everyday Life translated by S Elden, G Moore (Continuum, London)

Living Streets, 2011 Walk to Work Week 2011 http://www.livingstreets.org.uk/our-projects/walkingworks/walk_to_work_week

Lyons G, 2004, “Transport and society” Transport Reviews 24 485-509

Merleau-Ponty M, 2002 Phenomenology of Perception (Routledge, London)

Michael M, 2000, "These boots are made for walking ... mundane technology, the body, and human - environment relations" Body and Society 6107 - 126

Middleton J, 2009, “'Stepping in time': walking, time, and space in the city” Environment and Planning A 411943 - 1961

Middleton J, 2010, "Sense and the city: exploring the embodied geographies of urban walking" Social and Cultural Geography $11575-596$

Mokhtarian P L, 2005, "Travel as a desired end, not just a means" Transportation Research Part A: Policy and Practice $3993-96$

O'Dell T, 2009, "My soul for a seat: commuting and the routines of mobility", in Time, Consumption and Everyday Life: Practice, Materiality and Culture Eds E Shove, F Trentmann, R Wilk (Berg, Oxford) pp $85-98$

Potter J, 2004, "Discourse analysis as a way of analysing naturally occurring talk", in Qualitative Analysis: Issues of Theory and Method 2nd edition, Ed. D Silverman (Sage, London) pp 200 - 221

Prillwitz J, Barr S, 2009, "Motivations and barriers to adopting sustainable travel behaviour", WP 2, Department of Geography, University of Exeter, http://geography.exeter.ac.uk/prost/ downloads.html

Rankin K N, 2003, “Anthropologies and geographies of globalization” Progress in Human Geography $27708-734$

Ravaisson F, 2008 Of Habit (Continuum, London)

Reckwitz A, 2002, "Towards a theory of social practices: a development in culturalist theorizing" European Journal of Social Theory $5243-263$ 
Ryave A L, Schenkein J N, 1974, "Notes on the art of walking”, in Ethnomethodology Ed. R Turner (Penguin, Harmondsworth, Middx) pp 265-274

Saelens B E, Sallis J F, Frank L D, 2003, "Environmental correlates of walking and cycling: findings from the transportation, urban design, and planning literatures" Annals of Behavioural Medicine $2580-91$

Schatzki T, 1996 Social Practices: A Wittgensteinian Approach to Human Activity and the Social (Cambridge University Press, Cambridge)

Schwanen T, 2011, "Car use and gender: the case of dual-earner families in Utrecht, The Netherlands", in Auto Motives: Understanding Car Use Behaviours Eds K Lucas, E Blumenberg, R Weinberger (Emerald, Bingley, Yorks) pp $151-172$

Seamon D, 1980, "Body-subject, time-space routines, and place-ballets", in The Human Experience of Space and Place Eds A Buttimer, D Seamon (Croom Helm, London) pp 148-165

Sheller M, Urry J, 2006, "The new mobilities paradigm” Environment and Planning A 38 207-226

Shove E, 2005, "Changing human behaviour and lifestyle: a challenge for sustainable consumption?", in Consumption-Perspectives from Ecological Economics Eds I Ropke, L Reisch (Edward Elgar, Cheltenham, Glos) pp $111-132$

Shove E, 2010, "Beyond the ABC: climate change policy and theories of social change" Environment and Planning A $421273-1285$

Simmel G, 1971 The Metropolis and Mental Life (University of Chicago Press, Chicago, IL)

Simonsen K, 2004, "Spatiality, temporality and the construction of the city", in Space Odysseys: Spatiality and Social Relations in the 21st Century Eds J O Bærenholdt, K Simonsen (Ashgate, Aldershot, Hants) pp 43-62

Tf L, Transport for London (Mayor of London, London) 2004 Making London a Walkable City: The Walking Plan for London 2008 Walking in London

Thrift N, 2000, "With child to see any strange thing: everyday life in the city", in A Companion to the City Eds G Bridge, S Watson (Blackwell, Oxford) pp $398-409$

Thrift N, 2004, "Driving in the city" Theory, Culture \& Society 21(4/5) $41-59$

Transport 2000 Trust, 2003 Walking - The Way Ahead: Report from the National Seminar Series Transport 2000 Trust and Department for Transport, London

Vaiou D, Lykogianni R, 2006, "Women, neighbourhoods and everyday life" Urban Studies $43731-743$

Varela F, 1992, "The reenchantment of the concrete", in Incorporations Eds J Carry, S Kwinter (Zone Books, New York) pp 320-338

Verplanken B, Aarts H, Van Knippenberg A, Van Knippenberg C, 1994, "Attitude versus general habit: antecedents of travel mode choice" Journal of Applied Social Psychology $24285-300$

Verplanken B, Aarts H, Van Knippenberg A, 1997, "Habit, information acquisition, and the process of making travel mode choices" European Journal of Social Psychology $27539-560$

Watts L, 2008, "The art and craft of train travel” Social and Cultural Geography $9711-726$ 
Conditions of use. This article may be downloaded from the E\&P website for personal research by members of subscribing organisations. This PDF may not be placed on any website (or other online distribution system) without permission of the publisher. 